\title{
Thermal cameras in school laboratory activities
}

\author{
Jesper Haglund, Fredrik Jeppsson, David Hedberg and Konrad J Schönborn
}

\section{Linköping University Post Print}

\section{Tweet}

N.B.: When citing this work, cite the original article.

Original Publication:

Jesper Haglund, Fredrik Jeppsson, David Hedberg and Konrad J Schönborn, Thermal cameras in school laboratory activities, 2015, Physics Education, (50), 4, 424-430.

http://dx.doi.org/10.1088/0031-9120/50/4/424

Copyright: IOP Publishing: Hybrid Open Access

http://www.iop.org/

Postprint available at: Linköping University Electronic Press

http://urn.kb.se/resolve?urn=urn:nbn:se:liu:diva-119702 


\title{
Thermal cameras in school laboratory activities
}

\author{
J. Haglund, F. Jeppsson, D. Hedberg, \& K. J. Schönborn
}

\section{Postprint}

N.B.: When citing this work, please cite the original article.

Original Publication:

Haglund, J., Jeppsson, F., Hedberg, D., \& Schönborn, K.J. (2015). Thermal cameras in school laboratory activities. Physics Education, 50(4), 424-430.

http://dx.doi.org/10.1088/0031-9120/50/4/424

Copyright: IOP Publishing 


\title{
Thermal cameras in school laboratory activities
}

\begin{abstract}
Thermal cameras offer real-time visual access to otherwise invisible thermal phenomena, which are conceptually demanding for learners during traditional teaching. We present three studies of students' conduction of laboratory activities that employ thermal cameras to teach challenging thermal concepts in grades 4, 7 and 10-12. Visualization of heat-related phenomena in combination with predict-observe-explain experiments offers students and teachers a pedagogically powerful means for unveiling abstract yet fundamental physics concepts.
\end{abstract}

\section{Introduction}

Thermal science is central in many science education curricula and involves a range of core concepts in physics, chemistry and biology, such as heat and energy. Developing knowledge in this area is also crucial for grasping the challenges presented by global warming and finding solutions to pertinent environmental issues. However, it remains demanding for learners to conceptualize thermal phenomena (Yeo and Zadnik 2001), and we therefore need effective interventions in classrooms and laboratories.

Many school experiments in physics laboratory work are often heavily focused on measuring and representing quantities related to core concepts (e.g. plotting graphs, taking measurements). However, through the use of increasingly affordable hand-held thermal cameras, also known as infrared (IR) cameras, in exploring thermal processes, the focus suddenly shifts from a quantitatively-laden approach towards a more qualitative, user friendly, intuitive, and visually rich representation of abstract concepts, such as heat and temperature. Thermal imaging relies on detecting electromagnetic radiation from solid or liquid surfaces, from which their temperature may be derived by means of Planck's law of blackbody radiation (Vollmer and Möllmann 2010). Physics education research has recognized the potential of using IR cameras in physics teaching with laboratory exercises primarily aimed at the university level (Vollmer et al 2001, Möllmann and Vollmer 2007, Xie and Hazzard 2011, Pendrill et al 2012, Xie 2014, Vollmer and Möllmann 2013, Simon 2014, Vollmer et al 2004). To date, however, few studies have reported students' interaction with IR cameras, in particular in physics teaching at pre-university levels.

The aim of this paper is to present the design of hands-on laboratory classroom activities with thermal cameras and report results of student conduction of the activities in primary and secondary physics education.

\section{School laboratory activities with IR cameras}

Science education research has found that students tend to conflate heat and temperature into one undifferentiated heat-related conception (Shayer and Wylam 1981), paralleling historical interpretations of thermal phenomena (Wiser and Carey 1983). One phenomenon that has been particularly challenging for students to account for is the fact that metals feel colder at room temperature than many other materials (e.g. plastic or wood). Apart from the 
(erroneous) assumption of our sense of touch being an adequate thermometer, Engel Clough and Driver (1985, p 181) point out: 'quite simply students find it difficult to think of conduction of heat when they feel cold'. In response, Erickson (1985, p 59) called for a change in point of view:

If pupils were able to 'see' this phenomenon [that metals feel cold at room temperature] in terms of a transfer of energy from their body to the object, this sort of situation would likely be less of a problem than it seems to be at present.

In the light of the reported challenges with grasping why metals feel cold at room temperature, we thought that IR cameras might serve as a powerful teaching tool. With IR cameras, students would be able to see heat conduction through metal with their own eyes, rather than merely before their minds' eye. We designed a series of IR-camera laboratory activities based on the 'predict-observe explain' (POE) approach (White and Gunstone 1992). POE takes the form of the teacher first asking students to predict what will happen in the subsequent activity of interest. Next, the students observe what occurs while the activity is performed. Finally, the teacher encourages the students to explain their observations in light of their initial predictions (see Appendix A for an example worksheet of an IR-camera activity following the POE structure).

\section{$7^{\text {th }}$ graders experience heat transfer from thumbs to metal}

In the first IR-camera study, we asked two pairs of $7^{\text {th }}$ graders (12-13 years old) to perform three exercises in a POE fashion. The first exercise involved measuring the temperature of a piece of wood, a sheet metal knife, and a woollen beanie, which had been left indoors for some time. The second exercise involved thumb contact with the piece of wood and the knife for $2 \mathrm{~min}$ (see figure 1). The third exercise involved measuring three equivalent objects in chilly outdoors conditions. For comparison, one pair of students each viewed static IR images of the phenomena, and performed digital thermometer measurements, respectively (Schönborn et al 2014).
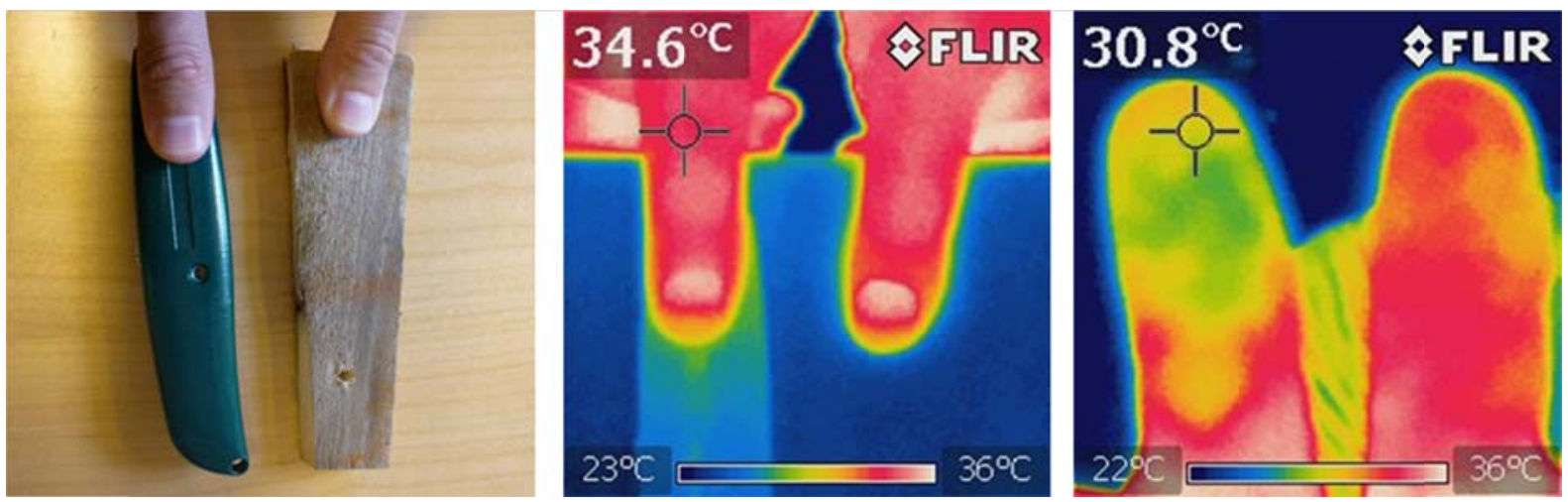

Figure 1. Photograph (left) and thermal image (middle) of thumbs in contact with a knife and a piece of wood, showing heat conduction through the metal, but not through the insulating wood; thermal image (right) of the thumbs, after having been in contact with the metal to the left, and with the wood to the right. 
As an outcome of the study, we found that all groups - with or without the use of IR cameras - expressed a cognitive conflict (Posner et al 1982) in that the metal felt colder than the wood and the woollen beanie, yet had the same temperature. Furthermore, the students who observed the heating of the knife with the IR camera (see figure 1), did not interpret this phenomenon in terms of a heat flow through the knife, but as the thumb heating the knife, the knife warming up, or noting the rising temperature. They did not spontaneously employ extensive thermal quantities, e.g. energy or heat, in their accounts. The frustration induced by the situation remained at the end of the session, which was clearly expressed by one of the pupils: 'But metal really is just colder!'

\section{$4^{\text {th }}$ graders learn about heat conduction and insulation}

In the next study, we developed a series of IR-camera laboratory activities in collaboration with a 4th-grade science teacher, and taught her two parallel classes ( $N=46$, ages 9-11 years) thermal science in accordance with the Swedish grade 4-6 curriculum, focusing on heat conduction and insulation of different materials. As a consequence of the somewhat discouraging outcome of the $7^{\text {th }}$ graders' interactions with IR cameras, we concluded that our laboratory activities would have to be accompanied by explicit teaching of a simple heat-flow model (Arnold and Millar 1996, Linn and Eylon 2011). Using the model, the pupils were told that heat tends to flow from warm objects to cold objects, with which they are in contact, and that insulators may be used to hinder such heat flow.

We used the POE approach in all exercises, including whole-class teaching of the heat-flow model and IR camera demonstrations, and in small-group settings, where the pupils interacted with the equipment and laboratory tasks together with one researcher or one of their regular teachers. In an introductory task focusing on getting to know the equipment and preparing for the concept of thermal equilibrium, the pupils were asked to select three objects in the schoolyard and measure their temperatures. The small-group laboratory tasks were:

- The knife and wood experiment, as developed for the $7^{\text {th }}$ graders.

- First placing one hand in cold water and the other in warm water, and then simultaneously submerging them into tepid water, the temperature of which is experienced differently with the two hands (see figure 2).

- Pouring hot water in a ceramic coffee mug and thin plastic cup (see Figure 2).
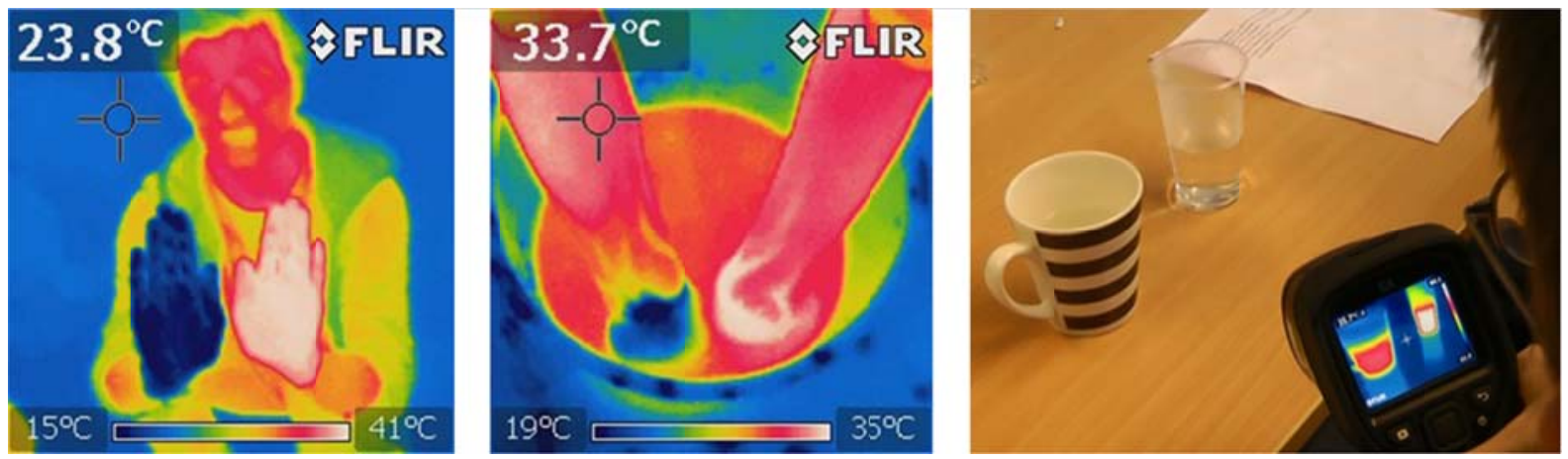

Figure 2. Thermal images of hands after they have been removed from cold and warm water, respectively (left); cold and warm hands placed in tepid water (middle); a student observing a coffee mug and a plastic cup containing hot water with a thermal camera (right). 
Our overall impression was that against the shared experience of the small-group laboratory exercises with the thermal cameras, many of the pupils came to adopt the taught heat-flow model in their explanations of the studied phenomena. At closer study of one of the groups as they interacted with the task of pouring hot water into the cup and mug, we found that they focused closely on the changing temperatures of the containers as they first warmed up (almost immediately in the case of the plastic cup) and then gradually cooled down (Haglund et al in press). In addition, they engaged in spontaneous 'instant inquiry' in the form of asking 'what ifs', such as what would happen if I blow on the warm water surface, and immediately get an answer by performing it and observing with the IR camera as the temperature quickly drops. Similarly, one of the pupils proposed that they should see what happens when they placed a pencil in the hot water. The pupils predicted that the pencil would 'take' or 'suck in' the heat, and that the surrounding water would get cooler, indicating their conception of the phenomenon as a heat-flow scenario.

\section{Thermal science and mechanics at upper secondary school}

We have also adapted the POE-based laboratory tasks used with the $4^{\text {th }}$ graders to upper secondary physics teaching (grades 10-12), and explored them with about 80 students. In addition to these tasks focusing on heat conduction, with this age group we have used the IR camera for students to experience dissipative processes, including:

- Observing 'heat streaks' appear and fade as they rub an eraser against a rough surface.

- Seeing a temperature increase (of about $4{ }^{\circ} \mathrm{C}$ ) as a metal ball is dropped onto asphalt (or a note pad) from the height of $2 \mathrm{~m}$ (see Figure 3), and accounting for the energy transformation occurring at the point of impact.

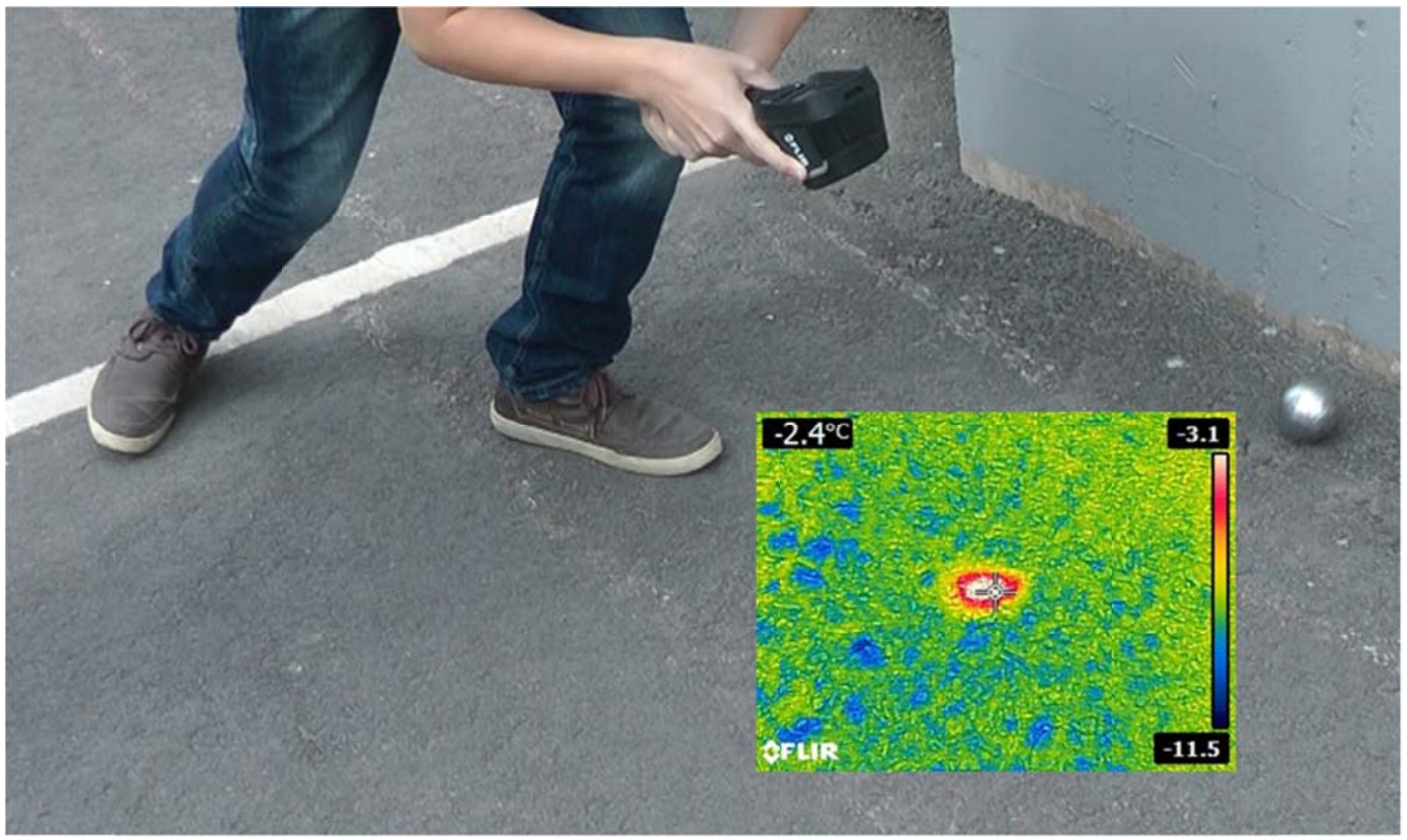

Figure 3. Photograph of a student directing the thermal camera to the point of impact of a metal ball with an asphalt surface. The inset displays the thermal camera image of a 'heat mark'. 
In traditional teaching it remains elusive for students to understand what happens to the kinetic energy during dissipative processes, involving e.g. non-elastic collisions or friction. Involved temperature increases are often not detectable through the sense of touch or traditional thermometers (Daane et al 2015). We have tended to attribute any energy losses sweepingly to friction or heat in physics teaching, but can now explicitly see a heat mark or streak with an IR camera. When studying the upper secondary students' interaction with the tasks and IR cameras, we noted that one aspect that characterized stronger groups was their tendency to employ microscopic explanations of the involved phenomena, e.g. heat conduction and friction. As a parallel to the $7^{\text {th }}$ graders' lack of a heat-flow model, we realized that the IR cameras have disciplinary affordance (Fredlund et al 2012) related to macroscopic thermodynamics concepts (e.g. heat and temperature), but not to microscopic ideas involving particle interaction. Other visualization technologies, such as molecular interaction simulations (e.g. Xie and Tinker 2006, Perkins et al 2006) would be more suited than IR cameras to make such microscopic phenomena visible to students.

\section{Constructing solar air preheaters in an upper secondary school project}

As part of an interdisciplinary activity drawing on technology, physics, and technical writing, a grade 12 class constructed solar-driven air preheaters, and then utilised thermal cameras to evaluate their designs for efficiency (Figure 4).
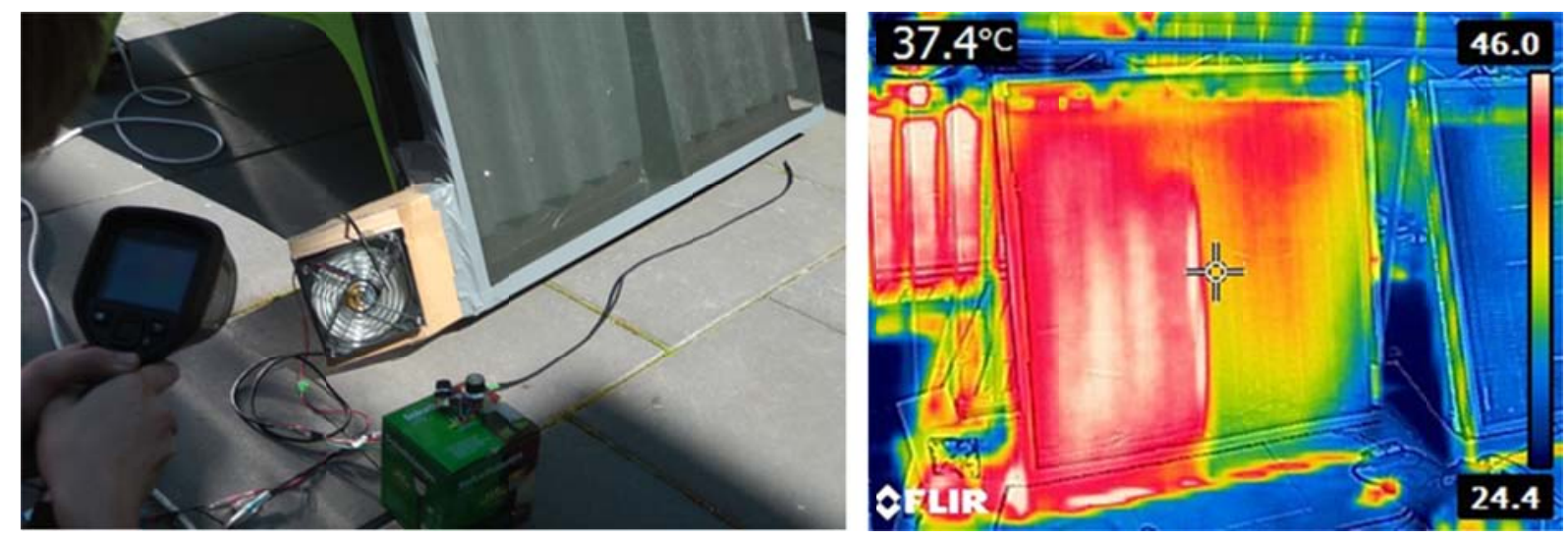

Figure 4. A group of students' air preheater design: photograph (left); thermal image of gradual heating of air taken from the bottom right (right).

All preheaters were propelled by electric fans placed in the intake of cold air or outlet of heated air. The students were able to see the preheaters' windows increasing in temperature and locate any heat leakages. Depending on the material and construction choices in their designs, they could evaluate which design was best relative to observed patterns of heat flow and use this visual information as a tool to improve the efficiency of their preheaters. In addition to seeing temperature increases, the students also noticed and discussed several thermal phenomena and concepts. For instance, on the day of evaluation of the constructions, the fan did not work for one of the groups, but with the help of the IR camera they inferred that there was still circulation of the air in their preheater, due to hot air rising; a case of heat convection. Even though the students experienced many thermal phenomena as part of the preheater project, this did not necessarily mean that they managed to connect them to the taught physical theory. The project and interaction with the IR cameras were found useful for understanding heat convection and radiation, but heat conduction remained challenging for the students. 


\section{Conclusions}

IR cameras provide an immediate visual feedback about complex thermal processes that are difficult for students to experience and learn about. Bringing IR cameras into the classroom as part of innovative activities enables students to actively explore abstract thermal concepts in a concrete and meaningful fashion. However, as found in the studies with the $7^{\text {th }}$ graders and the $12^{\text {th }}$ graders' air preheater projects, students do not see what they are not yet able to see, in these cases heat conduction. The use of IR imaging, just as any educational tool, has to occur hand in hand with age-appropriate teaching targeted at the students' level of conceptual understanding.

When introducing IR cameras in physics teaching, the degree of guidance will vary depending on the age of the students. Intriguingly, in a study of visitors' interactions with an IR-camera exhibit at a science museum, Atkins et al (2009) found detailed instructions to stifle the creativity, in comparison to the vibrant activity that was induced when the visitors could discover for themselves how to use the IR camera. A common reaction received when we present how IR cameras might be used in teaching goes along the lines of: 'Wow, I want one of these! How much do they cost?' The price of the types of hand-held IR cameras we have used (FLIR i3 and FLIR E4) is about $1000 €$, which admittedly amounts to a considerable cost for most schools. Recently, however, smartphone add-on IR cameras (FLIR ONE and Seek Thermal) have been launched in a more attractive price range (about $200 €$ ), making the technology increasingly viable in school settings.

\section{Acknowledgement}

We would like to thank Charles Xie, Anna Engvall Hårte and Björn Hållander for collaboration in developing the activities and Knut Neumann for sharing ideas about the ball drop activity, and all the participating students and their teachers for engaging with the exercises.

\section{References}

Arnold M and Millar R 1996 Learning the scientific "story": A case study in the teaching and learning of elementary thermodynamics Sci. Educ. 80 249-81

Atkins L J, Velez L, Goudy D and Dunbar K 2009 The unintended effects of interactive objects and labels in the science museum Sci. Educ. 93 161-84

Daane A R, McKagan S B, Vokos S and Scherr R E 2015 Energy conservation in dissipative processes: Teacher expectations and strategies associated with imperceptible thermal energy Physical Review Special Topics - Physics Education Research 11010109

Engel Clough E and Driver R 1985 Secondary students' conceptions of the conduction of heat: bringing together scientific and personal views Physics Education 20 176-82

Erickson G L 1985 Children's ideas in science, ed R Driver, et al. (Milton Keynes, UK: Open University Press) pp 55-66

Fredlund T, Airey J and Linder C 2012 Exploring the role of physics representations: an illustrative example from students sharing knowledge about refraction Eur. J. Phys. 33 657

Haglund J, Jeppsson F and Schönborn K in press Taking on the heat - a narrative account of how infrared cameras invite instant inquiry Research in Science Education

Linn M C and Eylon B-S 2011 Science learning and instruction: taking advantage of technology to promote knowledge integration (New York, NY: Routledge) 
Michael V, Klaus-Peter M and Detlef K 2004 Microwave oven experiments with metals and light sources Physics Education 39 500-8

Möllmann K-P and Vollmer M 2007 Infrared thermal imaging as a tool in university physics education Eur. J. Phys. 28 S37-S50

Pendrill A-M, Karlsteen M and Rödjegård H 2012 Stopping a roller coaster train Physics Education 47 728-35

Perkins K, Adams W, Dubson M, Finkelstein N, Reid S, Wieman C and LeMaster R 2006 PhET: Interactive simulations for teaching and learning physics The Physics Teacher 44 18-23

Posner G J, Strike K A, Hewson P W and Gertzog W A 1982 Accommodation of a scientific conception: Toward a theory of conceptual change Sci. Educ. 66 211-27

Schönborn K J, Haglund J and Xie C 2014 Pupils' early explorations of thermoimaging to interpret heat and temperature Journal of Baltic Science Education 13 118-32

Shayer M and Wylam H 1981 The development of the concepts of heat and temperature in 10-13 year-olds Journal of Research in Science Teaching 18 419-34

Simon A 2014 Electric current solves mazes Physics Education 49 443-6

White R and Gunstone R 1992 Probing understanding (London, UK: The Falmer Press)

Wiser M and Carey S 1983 Mental Models, ed D Gentner and A L Stevens (Hillsdale, NJ: Lawrence Erlbaum) pp 267-97

Vollmer M and Möllmann K-P 2010 Infrared thermal imaging: fundamentals, research and applications (Weinheim, Germany: Wiley-VCH)

Vollmer M and Möllmann K-P 2013 Characterization of IR cameras in student labs Eur. J. Phys. 34 S73-S90

Vollmer M, Möllmann K-P, Pinno F and Karstädt D 2001 There is more to see than eyes can detect - Visualization of energy transfer processes and the laws of radiation for physics education The Physics Teacher 39 371-6

Xie C 2014 The Concord Consortium. Infrared Tube. Available at: http://energy.concord.org/ir. (Accessed: 16 May 2014)

Xie C and Hazzard E 2011 Infrared imaging for inquiry-based learning The Physics Teacher 49 368-72

Xie C and Tinker R 2006 Molecular dynamics simulations of chemical reactions for use in education J. Chem. Educ. 83 77-83

Yeo S and Zadnik M 2001 Introductory thermal concept evaluation: assessing students' understanding The Physics Teacher 39 496-504 


\section{Appendix A. Worksheet - knife and wooden spoon}

Equipment: an infrared camera, a sheet-metal knife, and a wooden spoon

\section{Part 1}

Prediction: Touch the spoon and the knife briefly. What temperatures do you think they have?

Observation: Observe the spoon and the knife with the infrared camera. What temperatures do they have?

Explanation: Explain the outcome of the experiment. Did your observations differ from your predictions?

\section{Part 2}

Prediction: One of you will hold the knife and the spoon at their ends for 2 minutes. What will it look like on the screen of the infrared camera?

Observation: Hold the objects at their ends for two minutes, while the other members of the group observe with the infrared camera.

Explanation: Explain the outcome of the experiment. Was there a difference between the two objects? Did your observations differ from your predictions? 